Chapter 2

\title{
Design Thinking in Conceptual Design Processes: A Comparison Between Industrial and Engineering Design Students
}

\author{
Hao Jiang and Ching-Chiuan Yen \\ Additional information is available at the end of the chapter
}

http://dx.doi.org/10.5772/52460

\section{Introduction}

Design thinking is one of the most important issues in the fields of design research, as design expertise and creativity are mainly manifested through designers' cognitive processes when they are undertaking design activities, in particular during conceptual design stages [1, 2]. Majority of the design research community tend to model design thinking as a style of thinking underlining all design domains/disciplines, and complementary to scientific thinking and other non-design thinking [3-6]. Designing in fact comprises of various activities of multifaceted nature [7]. Variations of the thinking styles between different types of designers have been reported in many empirical design studies [e.g., 8 - 10]. Literature suggests that tertiary educational programs may contribute to the characteristics of thinking styles. Lawson's study indicates that design thinking may relate to learnt behaviors [7, 11]. Senior undergraduate architecture and science students demonstrated distinct problem solving strategies, while such disciplinary difference was not observed between first-year undergraduate architecture students and high school students [11]. Following the same rationale, this paper is interested in identifying possible effects of different design programs on shaping students' design thinking styles and the associated design strategies.

\section{Two design programs in the National University of Singapore (NUS)}

Designing is a complex human activity and encompasses a series of complex interactions between many factors or variables. Controlling some of those variables becomes necessary to provide a meaningful dataset to work with. This paper focuses on design thinking in concep- 
tual design activities in the domain of product design. Two relevant design programs are studied, i.e. Industrial Design (ID) and Mechanical Engineering Design (ME) from the National University of Singapore (NUS), which is consistently ranked as one of the best universities in Asia and the world. These design programs themselves also respectively hold a good reputation in their own fields.

Design thinking is implemented as one of the essential pillars in these two programs. Both programs value multi-disciplinary aptitude and strongly encourage their students to take modules offered by other faculties, such as humanity, business and management, to broaden their perspectives and repertoire of skills $[12,13]$. These two programs also collaborate with each other through joint design workshops and projects [14]. In addition,both programs champion a learning-by-doing approach in their curricula, while less relying on conventional lecture-based teaching and learning.

A closer examination is conducted by reviewing two capstone design courses: ID's "vertical design studio" and ME's "industry-sponsored projects". These two courses require students to undertake design projects on the basis of a small-scaled design teams (usually 2 5px). Faculty members and industry partners will co-supervise the projects. Many projects involve participation from other disciplines.
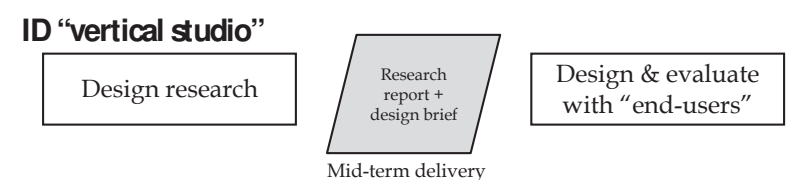

ME “industry-sponsored projects"
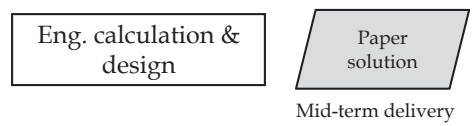

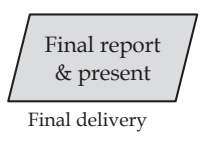

Final delivery

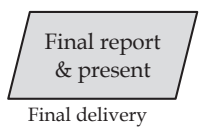

Figure 1. General schedules of ID and ME's design courses

The comparison of course plans demonstrates that the two courses have very different designing processes, as shown in Figure 1. ME projects require students to complete conceptual and embodiment design in the first half of course and submit a "paper solution" with detailed engineering calculations and drawings as their mid-term delivery. The foci of the second half of ME course is about evaluation and improvement of the proposed concept through a working prototype and further engineering calculations. ID's "vertical studio" emphasizes on the front end of designing, such as background research and problem scoping, user study, analysis of existing products, and technical and marketing inquiries. ID's mid-term delivery normally is a presentation of research findings about the problematic situation and design opportunities. The generation and development of design concepts/solutions are postponed to the second half of the course. 
Another difference identified is the "given problem" presented in the task description or design briefs. ID briefs usually are in a narrative form, describing trends of design and the problematic situations. The project brief provides an abstract vision, rather than a problem. The problem statement may be presented like "to satisfy higher order of hierarchy of needs" (ID Brief A), "a user-friendly product for the doctors and patients within the digital era" (ID Brief B), "design for a reasonably foreseeable future" (ID Brief C), "to question conventional notions of luxury and challenge its relevance in the modern day context" (ID Brief D), and "to explore and create new form of objects" (ID Brief E). To respond the clarity of problems, nearly all ID briefs explicitly demand that the brief/problem needs to be evolved and continuously developed throughout the whole process. The intended solutions are open-ended in the initial briefs, e.g., "a one-off object or a collection of objects" (ID Brief A), "no fixed category" (ID Brief C), or even "cool, crazy, stunning, unbelievable" (ID Brief E).

Instead of identifying the potential concepts, ME projects' task descriptions are much more structured. They are usually formatted in a form of checklist, such as backgrounds, objects, knowledge needed, deliveries, etc. The problems presented may have already specified the type, clients and detailed parameters of the envisioned solution, such as "a swing door stopper... to auto-close a swing door panel" (ME Task A), "a cooling system using ice as thermal energy storage" (ME Task B). The design requirements are clearly described and usually measurable, such as "converting a circular motion to a linear motion" (ME Task A). Some projects require to propose an application of an existing system in a particular situation, such as "an omni-directional 'Mecanum Wheel' robotic platform with Android platform control" (ME Task C), "a robot capable of taking videos for the creation of 3D images of underground sewerage pipe" (ME Task D), or a redesign/improvement, e.g., "to improve T-Bar turning device" (ME Task E).

\section{Examination of consequences of the curricular differences}

The differences identified in design briefs and task descriptions suggest that the two design curricula place different emphases on the "problem finding" activities, i.e., the ways in which problems are envisaged, posed, formulated, created [15, 16]. The examination of these two curricula's influences on students' habitual design behaviors thus focuses on how ID and ME students formulate and solve design problems when given the same set of design briefs and task descriptions. The design experiment was conducted in a design-studio-like setting, as shown in Figure 2. The unit of participation was a small design team formed by 2 final-year undergraduate students. Each team was asked to perform two conceptual design tasks, one for the existing market and one for future market. A detailed description of this experiment is presented in the authors' previous paper [17].

Literature shows there are two types of problem finding, i.e., the "reactive/passive" and "proactive/purposive" problem finding $[15,18]$. The former category refers to the problem recognition triggered by similarities between the current situation and a known problem type related to existing solutions/problem-solving repertories. "Purposive" prob- 
lem finding refers to proactive formulation of problems which are otherwise not existed or perceived as problems. Purposive problem finding is usually claimed to be "a key aspect of creative thinking and creative performance" [16] and perhaps more important than problem solving [19].

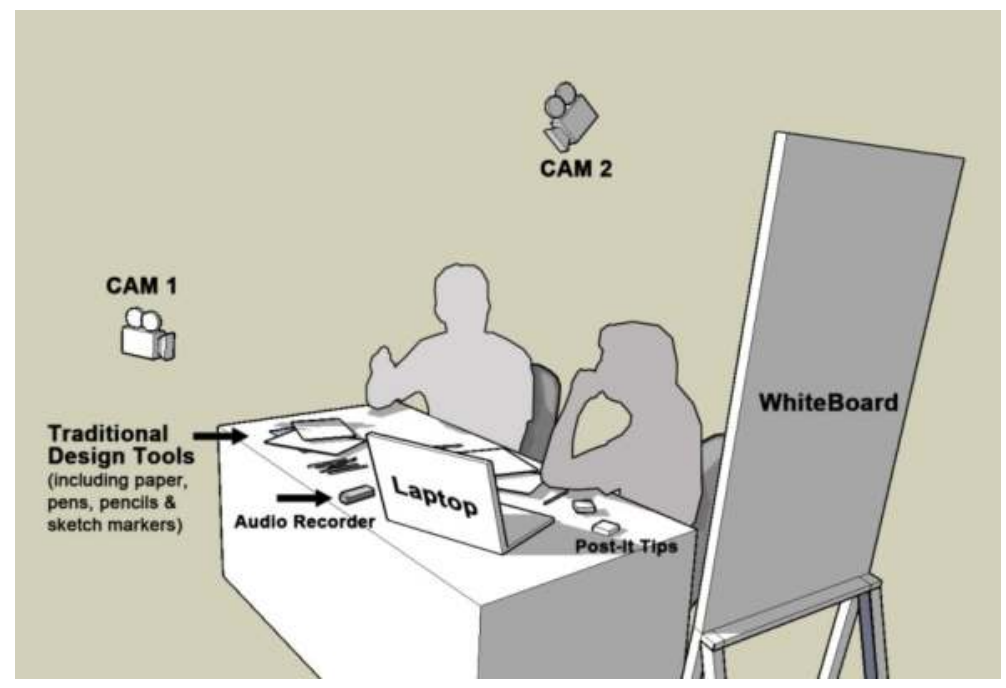

Figure 2. Experiment setup

The examination of problem finding or formulation applied Schön's reflection-in-action framework [20, 21]. Designers first "name" the relevant elements to set the boundary of problematic situation and then impose a "frame" to understand the context as well as determining actions towards solution. The analysis will focus on the quantity of named elements and how the relationships of these elements are articulated to stimulate designing processes. A small quantity of named elements and relatively direct mapping to design specifications suggest that designers do not spend much effort to proactively formulate their "own" problems to work on.

The analysis of solution development stages of designing focuses on the trajectory in which design ideas/concepts evolve. Oxman[22] proposed a multi-level structure of design knowledge from specific, context dependent precedents to more abstract, context-independent ones, as shown in Figure 3. Two distinct approaches of designing can be defined with regard to the form of the initial solution, i.e., a schema-driven refinement and a case-driven adaptation [23, 24]. The former approach starts with a highly abstract concept (i.e., a schema), and follows with a sequence of "refinement" operations to "particularize" the initial schematic state into a detailed description of a specific product $[23,24]$. The latter refers to a sequence of adaptions made to transform a rather detailed concept (i.e., a case) to work in a new situation. 
High level concept/ schema

- Cognitive, conceptual

Formal prototypes:

- Non-contextual

Functional prototypes:

- Functional context

Precedents:

- Highly contextual

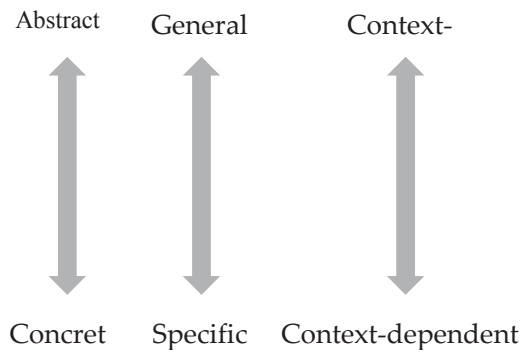

Figure 3. A structure of prior knowledge in design (adapted from [22])

Designing process transforms human needs or desires into a specification of physical embodiment. The inspiration source and form development process play an important role determining the final solution of the product. An additional analysis is then conducted to compare the "conceptual distance" between the main inspiration source and the final outcomes. This provides a coarse indicator for the design creativity.

\section{Problem formulation: Framing versus clarification}

Design problems have long been recognized as ill-defined [25], ill-structured [26] or "wicked" $[27,28]$. A typical design problem usually consists of determined, undetermined and "underdetermined" elements $[29,30]$. The formulation of a workable design problem seems to be the first step of the designing process. Designers need to understand the problematic situation and identify the relevant considerations. Table 1 lists the elements that each team used to make sense of the initial design brief.

ID teams seemed to study the design problem from contextual points of view. They were observed spending a large amount of cognitive efforts and time to go through the problem space (e.g., potential user's profile and possible usage contexts), and to explore the potential opportunities to create something new and appropriate (cf. [17, 31]). Their problem analysis and framing activities resembled a semi-structured process, including "naming" and "framing" activities [20, 21, 30, 32]. "Mind maps" (a graphic tool to stimulate creativity and idea generation [33]) were often used to assist the discussions during this period. Figure 4 presents two examples of the graphic tools applied in early episodes of ID teams' design sessions. The main branches of graphs in the Figure show how ID teams organized their thinking process and identified the aspects of design that need to be considered. Lateral/divergent thinking [34] was demonstrated in this period which mainly aimed to enlarge the problem space. These identified elements mainly concerned about end users and potential usage contexts, rather than directly related to characteristics of design solutions. 


\begin{tabular}{|c|c|c|c|c|}
\hline Session \Team & 1 & 2 & 3 & 4 \\
\hline \multirow{8}{*}{$\begin{array}{l}\text { ID,Task } 1 \\
\text { (existing } \\
\text { market) }\end{array}$} & Context & Who & People & People \\
\hline & People \& lifestyle & Why & Type of coffee & Types of coffee \\
\hline & When & When & Ways to make coffee & Ways to make coffee \\
\hline & What (small, & Where & Ways to drink coffee & How to enrich experience \\
\hline & personalized) & What & Look & \\
\hline & How (dispense) & Making process & Fun stuffs & \\
\hline & Sensory experience & & Market analysis & \\
\hline & (aroma) & & Technology & \\
\hline \multirow{6}{*}{$\begin{array}{l}\text { ID, Task } 2 \\
\text { (future market) }\end{array}$} & Places & Context (one the go/ & Who & People \& lifestyle \\
\hline & Physical/digital & not on the go) & What (electronic vs non- & 5 Senses (visual, sound, \\
\hline & Intuitive interaction & Type (electric vs non- & electronic) & smell, touch \& taste) \\
\hline & Game & electric) & Where & Analysis of existing \\
\hline & Past/now/future & Market trend & How (passive vs active) & products \\
\hline & Sensory experience & Interactivity & Sensory & $\begin{array}{l}\text { Features (existing, maybe } \\
\text { to have) }\end{array}$ \\
\hline \multirow{3}{*}{$\begin{array}{l}\text { ME,Task } 1 \\
\text { (existing } \\
\text { market) }\end{array}$} & Target user & Target user & Target user & Target user \\
\hline & Type of coffee maker & & Sleek stuffs & Size \\
\hline & Size/dimension & & Size & Cost \\
\hline \multirow{4}{*}{$\begin{array}{l}\text { ME,Task } 2 \\
\text { (future market) }\end{array}$} & Types of relevant & \multicolumn{2}{|c|}{ Types of entertainmentAR/VR } & Type of entertainment \\
\hline & products & \& products & Portable size + large & Feature (portable, easy to \\
\hline & Technology (VR) & & display & use) \\
\hline & Size (portability) & & Interactive & \\
\hline
\end{tabular}

Table 1. Elements identified to define the design problem
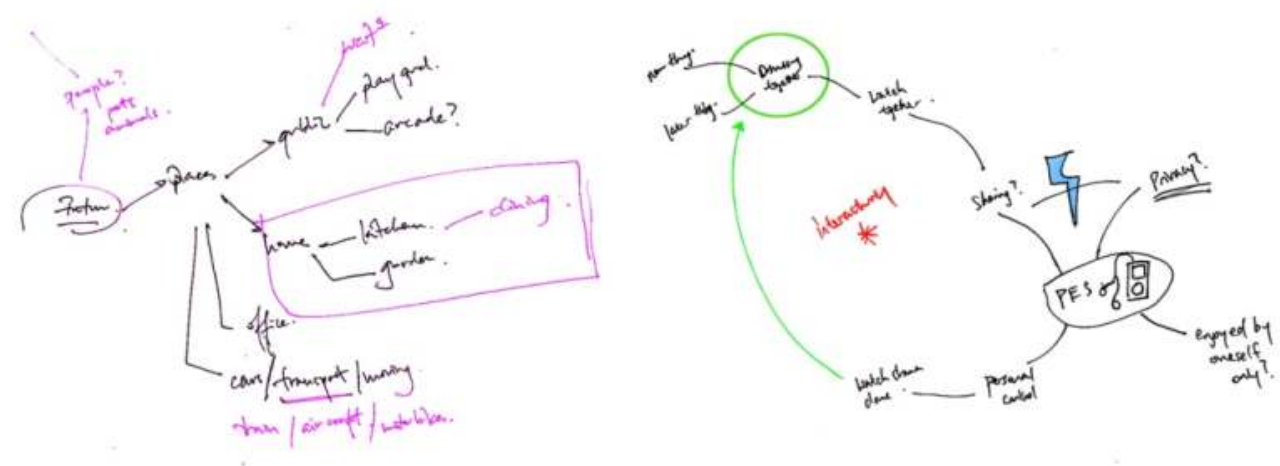

Figure 4. Mind maps used in ID team's problem framing 
After identifying the key aspects required to be considered, ID teams then examined the relationships between the "named" elements and "frame" the design space in which ideation and concept development was conducted. The colored lines/texts in Figure 4 labeled designers' endeavors of connecting the identified element to formulate a coherent design "frame" that facilitate tentative design "moves" towards the solution [20, 21].

Problem analysis and framing in the ID sessions was semi-structured. Though the search of pertinent elements aimed to systematically explore the problem, it was never intended to be exhaustive. Instead, a set of particular design problem probes were used, such as humancentric factors, sensory experience, interaction, emotion, etc. (cf. Table 1). Once an promising opportunity was identified, ID teams would take "opportunistic" moves [35, 36] and propose some tentative solutions (usually in abstract forms) accordingly. There is no evidence showing ID teams may stick to a rigidly structured systematic process.

ME teams put less emphasis in understanding the design problem than ID teams did. The issues discussed in the early episodes (Table 1) were either prescribed in the design brief, such as "target users" and "types of entertainment", or related to syntactic attributes of product, such as "size/dimension" and "technology". They focused on the clarification of the problem stated in the initial task description than proactively explore the problematic situation from various perspectives. They quickly made a checklist-like "specification", which was used later to evaluate whether or not their solution fulfilled these requirements. Two examples of ME teams' named list are presented in Figure 5.
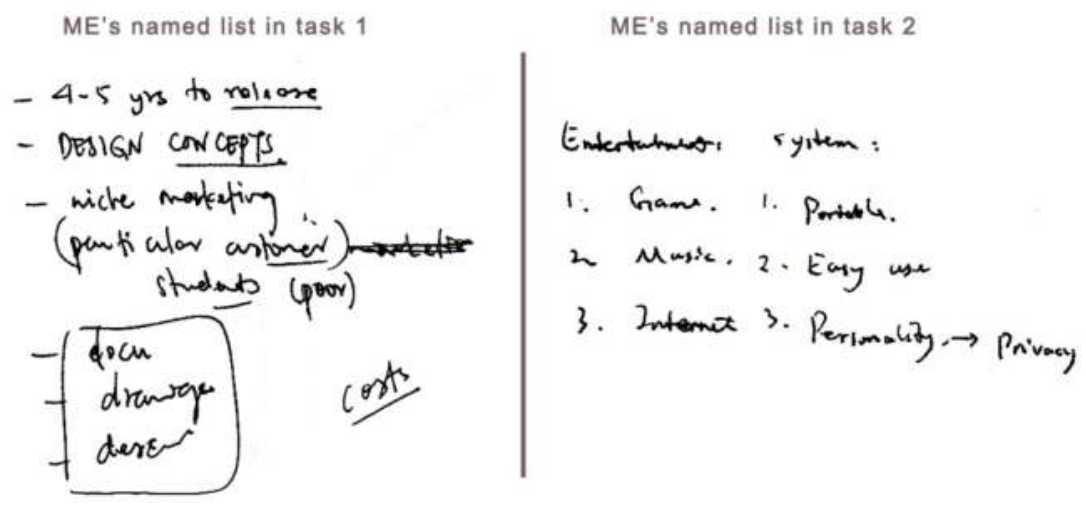

Figure 5. Specifications proposed in ME team's problem analysis

The different quantities of ID and ME teams' named elements reflect an attitudinal difference about the role of a design brief between ID and ME students. ME teams tended to treat the initial design brief as a given problem, though it may not provide a completed picture. What they ought to do is to fill the missing information and turn it into a set of measurable criteria. The stated problem was thus remain unchanged and can facilitate solution development. The "problem framing", i.e., selectively viewing a situation from various ways [20, 21], were not 
observed in ME sessions. ID students, on the other hand, consideredthe design problem as an imperative to innovation. The ID problem may constantly evolve when the designing process progressed. During the concept development stage, ID teams rarely made an explicit comparison between their solution and the formulated problem.

\section{Solution development: "Schema-driven" versus "case-driven"}

Preliminary exploration of design observations indicates that most design teams (both ID and $\mathrm{ME}$ ) seldom changed their strategies when they encountered with different design tasks, though they more elaborated their solution in the design targeting at the existing market than the design for the future market. In general, design concepts were incrementally evolved from initial ideas. The difference between ID and ME's design sessions were mainly observed in the forms of their initial ideas or concepts.

As mentioned in the last section, ID teams mainly explored user and contextual issues in the early episodes of designing. The initial ideas or "primary generator" [37] proposed by them were usually highly abstract and conceptual, such as sensory experience (shown in Figure 6, left). The left panel of Figure 7 demonstrates a trajectory in which an ID concept was developed. The red arrows and annotations were labeled by the authors to visualize the flow of ideas. Many design alternatives were explored and developed in parallel. The abandoned ideas were not shown in this Figure. The keywords underlying this design were "aroma" (smell), "veil of mist" (visual) and "cute" forms. These abstract ideas were thus slowly embodied and refined through a series of thumbnails and sketches, though designers may go back and forth between different levels of abstraction.

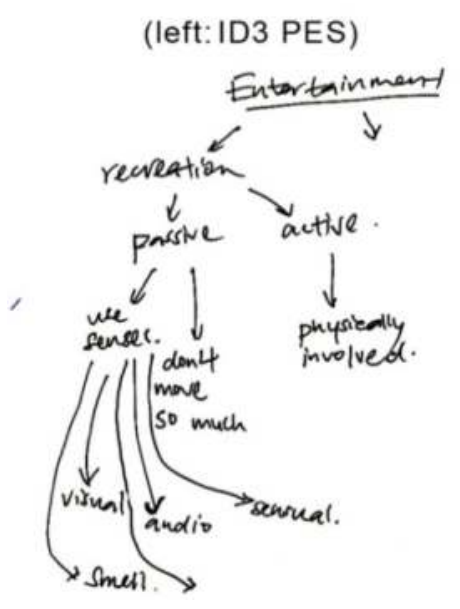

(right:ME1 PES)

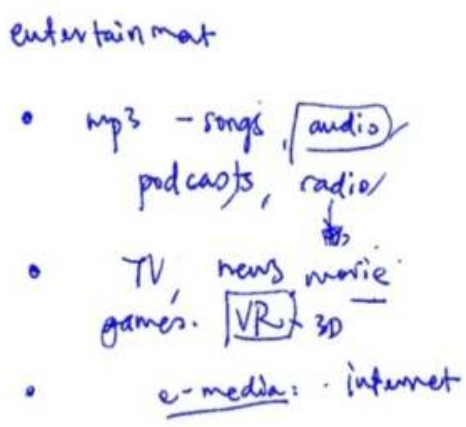

Figure 6. Two notes that assist the problem formulation process (left: ID session, right: ME session) 


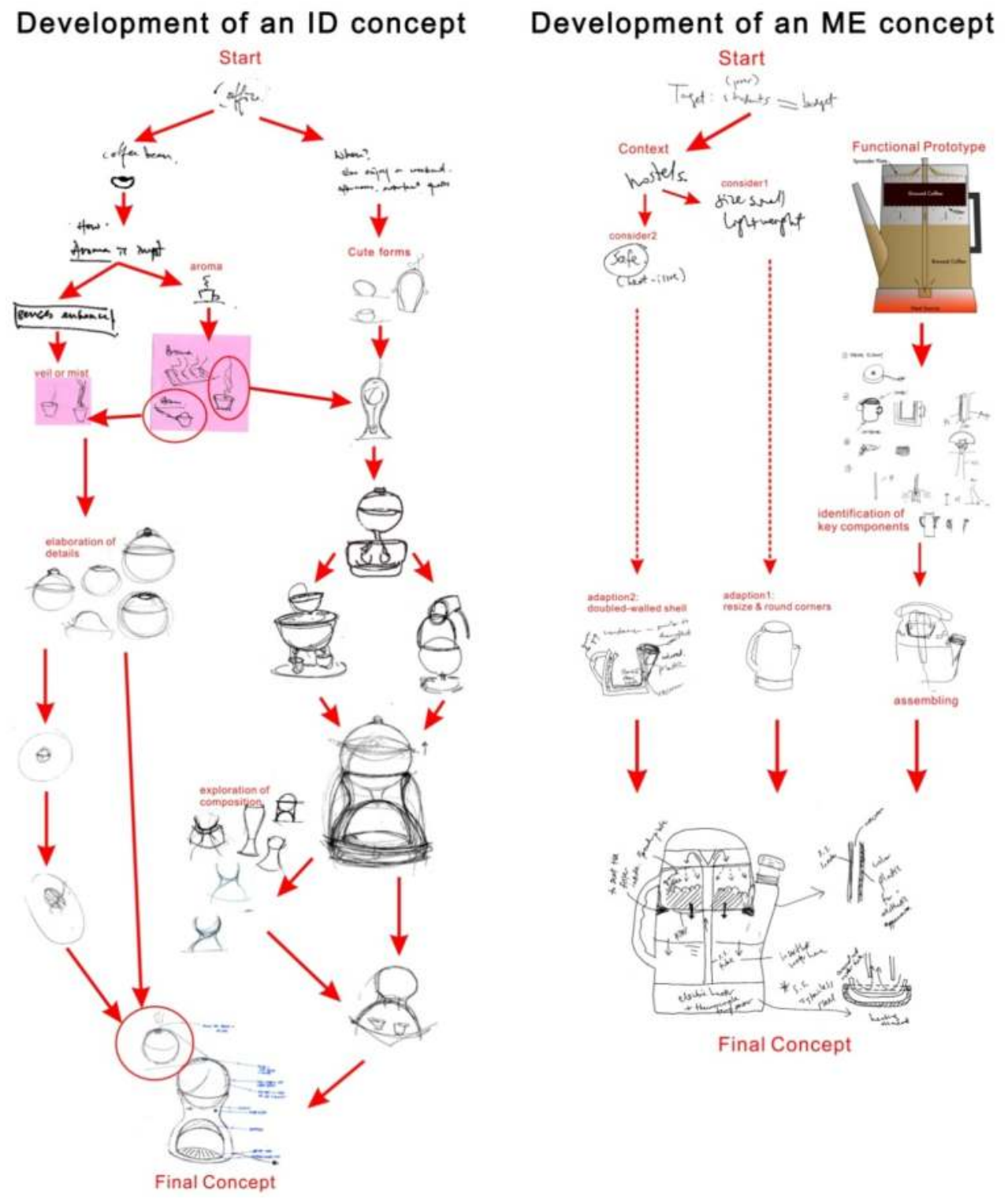

Figure 7. Two exemplar processes of concept development

During the problem analysis stage, ME teams tended to use specific precedents to understand the problematic situation. For example, in the right panel of Figure 6, a ME team used existing devices of MP3, VR, e-media, etc. to define the problem space of the design of a future entertainment device. Different from ID's "general to specific" process, ME teams' proc- 
esses were usually a "specific to specific" process, i.e., adapting a rather detailed precedent or "functional prototype" to fit the current situation. This approach also refers to case-based reasoning [23]. The right panel of Figure 7 demonstrates an adaption process of designing a coffee maker on the basis of a functional prototype(i.e., a structured form of prior knowledge in design [22], cf. Figure 3). Adaptions were made with regard to considerations related to the target situation. For example, the size was scaled down to meet a single-person usage. Components, such as the shell, were modified to cut the cost. Much fewer design alternatives were observed in ME's designing processes.

In short, the solution development of ID sessions generally resembled a schema-drive refinement process, and that of ME sessions tended to follow a case-driven adaptation process $[23,24]$.

\subsection{The inspiration sources}

Figure 8 displays the main inspiration sources and the final designs from ID and ME teams. The concepts are presented in sketches and inspiration sources are represented with related photos. The association between their concepts with the inspiration sources was assisted with qualitative analysis of design processes, not just what students claimed in the concept presentations.

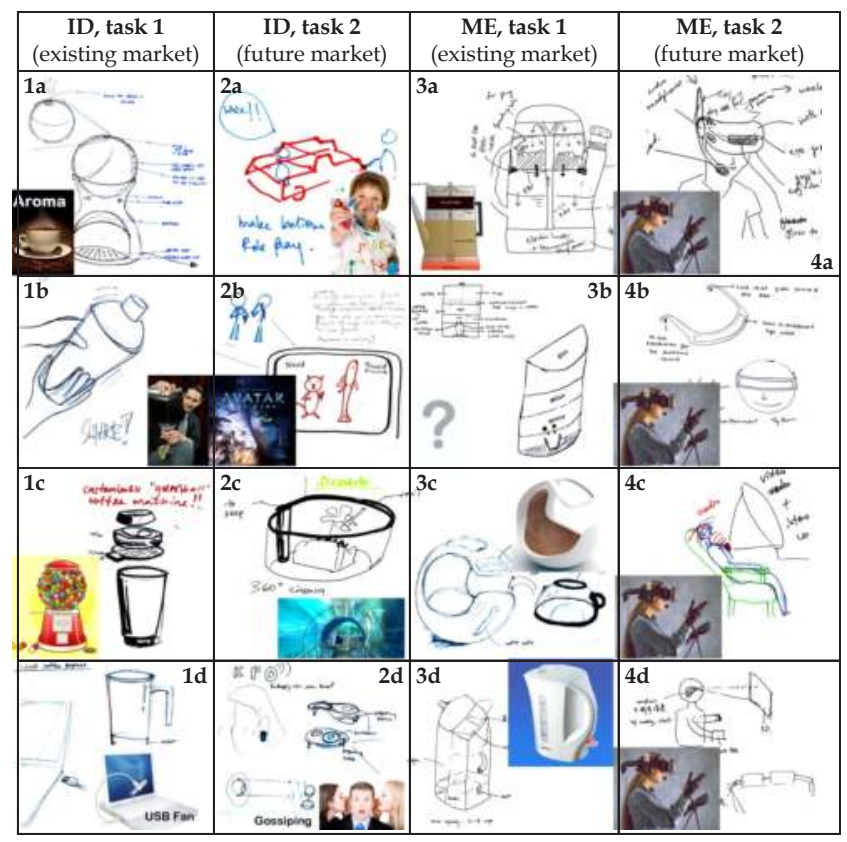

Figure 8. Design outcomes and their inspiration sources 
Figure 8 shows that ID teams tended to drive their designs with a verb (e.g., experience or actions) rather than a noun [38]. For example, they proposed ideas like to "enjoy the aroma" from nice coffee (Fig. 8, 1a), to "shake" like a bartender (Fig. 8, 1b), to "refill" coffee powder like a gumball machine (Fig. 8, 1c), to "paint or draw" like a kid (Fig.8, 2a), to "share gossips" with friends (Fig.8, 2d), etc. Even when they generated forms by analogizing, it was usually undertaken in a very abstract level. As demonstrated by Figure 9, it was the feeling or emotional response that designers tried to recreate, rather than to duplicate the specific forms.
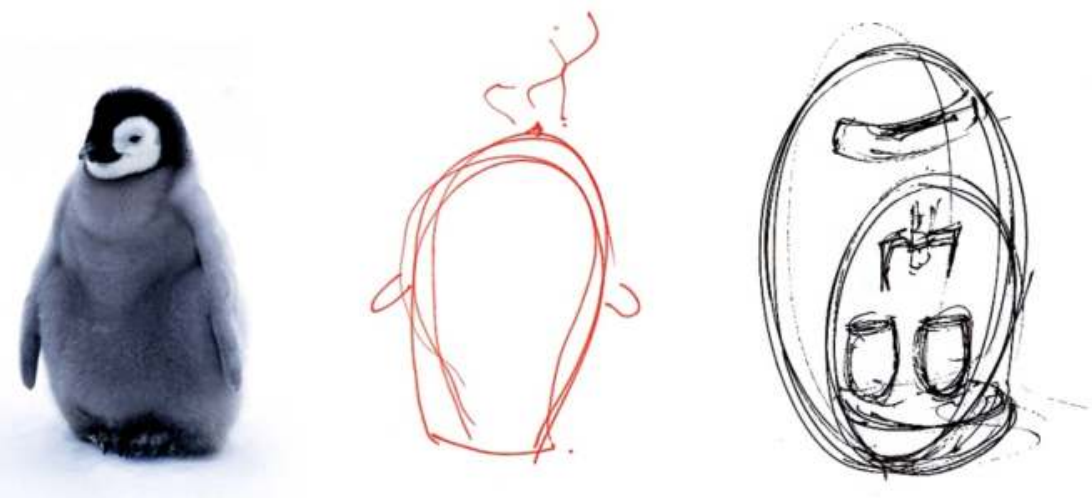

Figure 9. An inspiration source and the implements in an ID designing process

ME teams tended to build solutions on the basis of adaptation from existing products. They seemed to use product morphing or variant method [39, 40], and tended to incorporate salient features of existing products in their designs. Some incremental modifications were made, but the overall system architecture [41] were often kept untouched. Their designs were thus mainly redesigns, or "variant" / "adaptive" designs [40]. All ME teams displayed a very high degree of similarity in their future product solutions, i.e.,a goggle-based VR system for the future entertainment design. In the design for the existing market (a coffee maker), two teams recreated a simplified version of existing products to reduce the manufacture costs. Though ME tream3 located their inspiration source outside of coffee-related products for their coffee maker concept, they almost duplicated the form of a cradle and squeezing the coffee making components into this form abruptly, as shown in Figure 10.

The above results suggest that different types of innovation strategies were preferred between these two groups of students and the preferences seemed to be independent from the nature of design tasks. ID teams seemed to be more interested on radical innovation and their designs were less attached to available design precedents. This claim echoed with Purcell and Gero's [10] study of precedence fixation effect. ME participants may mimic some characteristics of inspired sources directly and ID students shown otherwise. 


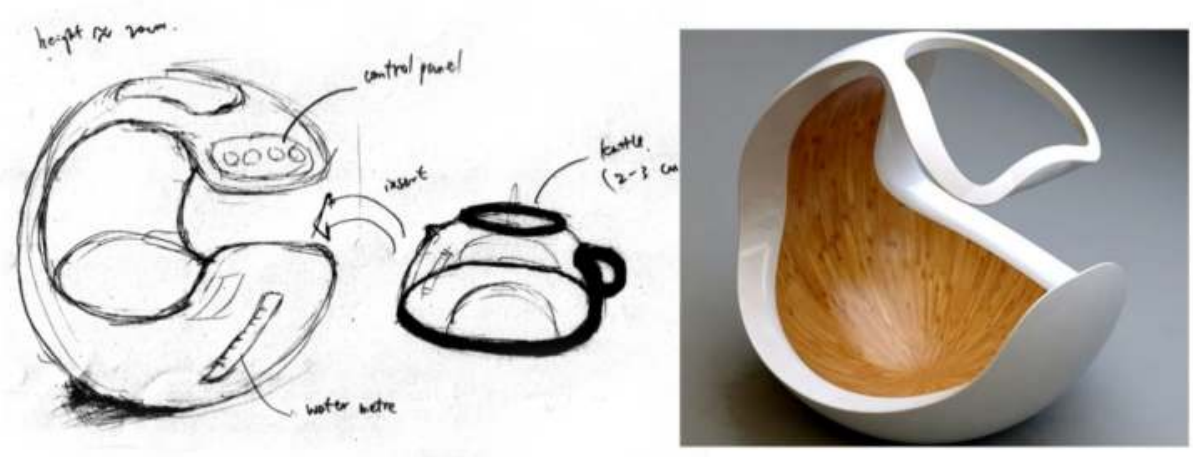

Figure 10. An ME team'scoffee maker concept and its inspiration source

\section{Discussions}

The qualitative examination of ID and ME teams' conceptual design processes suggests that design curricula have significant impact on senior design students' habitual design behaviors. Independent of which design task they encounter with, students' designing processes generally resembled the schedule of their capstone design courses. ID teams spent considerable time and efforts to make sense of the problematic situation and purposively deferred generation of solutions or partial solutions in the stage of problem framing. ME teams, on the contrary,tended to adopt a solution-oriented "problem structuring" strategy [42]. They were more likely to treat the given design brief as the mission and clarify it with envisioned solutions.

The observed behavioral differences between ID and ME students were consistent with their perceptions reported in the pretest questionnaires and follow-up interviews (cf. [43]). Though sharing similar terminologies and designing process models, ID and ME students held quite different understanding of design and designing. ME participants often held a traditional "problem-solving" view of designing. Their reports implied that the problem situations should be already prescribed in design brief, and their job is to recognize them and generate a feasible solution accordingly. ME students also tended to consider the designed product as a selfcontained system, to some extent detached themselves from relevant users and contexts. On the contrary, ID students apprehended design from the perspective of its ultimate aim, i.e., "the improvement of human quality of lives" (excerpted from an ID session'sconversation). The role of user (human) and usage context were usually more emphasized than that of a product per se.

Connecting these findings to the design literature, the problem formulation processes of ID and $\mathrm{ME}$ sessions may respectively resemble the two design paradigms, i.e., relation-in-action andproblem solving [44]. ME teams mainly clarified the problem to be solved, whereas ID 
teams may treat it as a start point and tended to expand and reformulate the problem based on their investigation. Roozenburg and Dorst[32] argued that "problem framing" concept is proposed to challenge "technical rationality", and primarily views design as a socio-cultural construct [20, 21]. ME students, however, tend to view product as a technical/physical construct and focused on syntactic aspects of design. Problem solving model of designing perhaps is more appropriate for the technically-oriented design [30].

\subsection{Teaching styles of ID and ME programs}

As stated earlier, NUS ID and ME programs both champion an immersive hands-on approach of teaching and learning, while less relying on traditional lectures. Using research's terminology, the teaching styles of these two programs fall into an "inductive" approach, which learning is characterized by student-centered, active learning and collaborative learning [45, 46]. The different emphases on design problems, or varying degrees of "structuredness"/ "openness" of the problem, further distinguish ID and ME's teaching into two related but different inductive approaches, i.e., problem-based and project-based ones[45, 46]. Problembased teaching/learning is a student-centered pedagogical approach that assumes the "centrality of problems" to learning [47]. Students work in teams to explore an open-end, illstructure, complex (real-world) problem that usually requires knowledge from various disciplines/domains $[48,49]$. A problem-based curriculum is organized around problems, and the learning process is mainly self-monitored and self-directed.

Project-based teaching/learning involves an assignment leading to the production of a final product $[45,46]$. It may be subdivided into three categories according to high to low levels of student autonomy, i.e., guided project, independent project and independent inquiry [50]. The last form, independent inquiry, is overlapped with problem-based learning.

The problem statements in project-based learning are relatively well defined and the needed knowledge may be previously acquired in the past courses. ME industry projects (cf. Section 2), for example, roughly defined the scope of knowledge needed, e.g., mechanical design, heat transfer, etc. ID "vertical studio" more expects students to make speculative and exploratory propositions, such as to question the old definition of problem in the modern context or explore the vision of future. It is not about to solve a problem, but to define what the problem is. The evaluation of ID course is thus more qualitative than that of ME projects, which requires more precise and quantitative calculations.

Some researchers recommend engineering education adopting problem-based teaching/ learning approach to better prepare their students for complex real-world problems [e.g., 51]. Empirical studies have confirmed that problem-based learning has positive effects on the selfdirected problem solving skills and tacit knowledge, but some negative effects are also found in the mastery of declarative knowledge [52]. Compared to speculative nature of ID, more precise requirements in engineering design more relies on a robust base of scientific knowledge. The failure of engineering design usually has severe consequences of huge cost or even human lives. Several empirical studies also show that experienced engineering designers may heavily rely on the proven solutions and make incremental refinements [53, 54]. Meanwhile, ID is much more tolerant of failure and willing to take risks. The failure of an ID concept usually 
has a gentler consequence than an engineering failure. This may partially account that ID studio course is more problem-based teaching/ learning whereas ME capstone course is more project-based teaching/ learning.

On the other side, the increasing demand of interdisciplinary design collaborations requires designers to better understand or appreciate their neighboring disciplines, in order to form a common ground for effective collaborations. Some fused design curricula are proposed accordingly. A design-centric engineering curriculum (DCC), for example, is recently launched by the NUS Faculty of Engineering. Many elements of design studio's approach are grafted onto engineering design courses to enhance engineering students' capabilities of "identifying and defining problems and formulating innovative and creative solutions" [55]. ID's "Design Thesis Project" module also raises the requirements on ID students' ability to develop and implement an appropriate, well-planned ID solution within the constraints of a "real world" framework of social, environmental, commercial and industrial issues, rather than simply proposing a good concept.

\section{Author details}

Hao Jiang and Ching-Chiuan Yen

Division of Industrial Design, National University of Singapore, Singapore

\section{References}

[1] Cross N. Understanding design thinking. In: Guerrini L. (ed.) Notes on doctoral research in design: Contributions from the Politecnico Di Milano. FrancoAngeli; 2011. p19-37.

[2] Cross N. Expertise in design: An overview. Design Studies 2004; 25(5): 427-41.

[3] Owen C.L. Design research: Building the knowledge base. Design Studies 1998; 19(1): 9-20.

[4] Owen C.L. Design thinking: Notes on its nature and use. Design Research Quarterly 2006; 1(2): 16-27.

[5] Archer L.B., Baynes K., Roberts P., editors. A framework for design and design education: A reader containing key papers from the 1970s and 80s. Wellesbourne: The Design and Technology Association; 2005.

[6] Cross N. Designerly ways of knowing. Basel: Birkhauser; 2008.

[7] Lawson B.R. How designers think: Demystifying the design process. 4th ed. Oxford: Elsevier/Architectural Press; 2006. 
[8] Akin Ö. Variants in design cognition. In: Eastman CM, McCracken WM, Newstetter WC. (eds.) Design knowing and learning : Cognition in design education. Oxford: Elsevier Science Ltd.; 2001. p. 105-24.

[9] Akin Ö. Variants and invariants of design cognition. In: McDonnell J, Lloyd P. (eds.) About: Design: Analysing design meetings: CRC Press; 2009. p171-92.

[10] Purcell T., Gero J.S. Design and other types of fixation. Design Studies 1996; 17(4): 363-83.

[11] Lawson B.R. Cognitive strategies in architectural design. Ergonomics. 1979; 22(1): 59-68.

[12] NUS ME. Bachelor of engineering (mechanical engineering): Degree requirement. http://me.nus.edu.sg/ prospectivestudent_undergrad_req.php/ (accessed July 12, 2011).

[13] NUS DID. The synergistic three-pronged approach. 2010. http://nusdid.edu.sg/ whynusdid/ ourapproach.htm/ (accessed July 12, 1011).

[14] Fuh J.Y.H., Lu L., Quan C., Lim S.C. Product design for industry: The NUS experience. In: Proceedings of the Engineering Capstone Design Course Conference; June 2007.

[15] Getzels J.W., Csikszentmihalyi M. The creative vision: A longitudinal study of problem finding in art. New York: John Wiley \& Sons Ltd; 1976.

[16] Jay E.S., Perkins D.N. Problem finding: The search for mechanism. In: Runco MA. (ed.) The creativity research handbook. Cresskill, N.J.: Hampton Press; 1997. p. 257-93.

[17] Jiang H., Yen C.C. Understanding senior design students' product conceptual design activities: A comparison between industrial and engineering design students. In: the 2010 Design Research Society (DRS) international conference "Design \& Complexity"; 7-9 July 2010; Montreal, Canada.

[18] Kleindorfer P.R., Kunreuther H.C., Schoemaker. P.J.H. Problem finding and alternative generation. In: Kleindorfer PR, Kunreuther HC, Schoemaker. PJH. (eds.) Decision sciences : An integrative perspective. Cambridge: Cambridge University Press; 1993. p24-63.

[19] Runco M.A., eiditor. Problem finding, problem solving, and creativity. Norwood, N.J.: Ablex Publishing Corporation; 1994.

[20] Schön D.A. Designing as reflective conversation with the materials of a design situation. Knowledge-Based Systems 1992; 5(1): 3-14.

[21] Schön D.A. The reflective practitioner : How professionals think in action (Paperback ed.). Aldershot, U.K.: Ashgate; 1991. 
[22] Oxman R.E. Prior knowledge in design: A dynamic knowledge-based model of design and creativity. Design Studies 1990; 11(1): 17-28.

[23] Ball L.J., Ormerod T.C., Morley N.J. Spontaneous analogising in engineering design: A comparative analysis of experts and novices. Design Studies 2004; 25(5): 495-508.

[24] Oxman R.E., Oxman R.M. Refinement and adaptation in design cognition. Design Studies 1992; 13(2): 117-34.

[25] Eastman C.M. Cognitive processes and ill-defined problems: A case study from design. In: Proceedings of the First International Joint Conference on Artificial Intelligence (IJCAI). Bedford, MA: MITRE; 1969.

[26] Simon H.A. The structure of ill-structured problems. In: Cross N. (ed.) Developments in design methodoligy. Chichester; New York: John Wiley \& Sons Ltd; 1984. p145-66.

[27] Buchanan R. Wicked problems in design thinking. Design Issues 1992; 8(2) :5-21.

[28] Rittel H.W.J., Webber M.M. Planning problems are wicked problems. In: Cross N. (ed.) Developments in design methodology. Chichester ; New York: John Wiley \& Sons Ltd; 1984. p135-44.

[29] Dorst K. The problem of design problems. In: Cross N, Edmonds E. (eds.) Expertise in design: Design thinking research symposium (DTRS) 6; 2003. p135-47.

[30] Lawson B.R., Dorst K. Design expertise. Oxford: Architectural Press; 2009.

[31] Yen C.-C., Jiang H. Examining the dynamic processes of conceptual design: An ontologically-based protocol analysis. In: Peng Y-H, Chen C-H. (eds.) Proceedings of 2011 IDA (International Design Alliance) congress education conference. Taipei, Taiwan: Taiwan Design Center; 2011. p103-13.

[32] Roozenburg N.F.M., Dorst K. Describing design as a reflective practice: Observations on schon's theory of practice. In: Frankenberger E, Badke-Schaub P, Birkhofer H. (eds.) Designers : The key to successful product development. New York: Springer; 1998. p29-41.

[33] Buzan T., Buzan B. The mind map book: Unlock your creativity, boost your memory, change your life London: BBC Active; 2010.

[34] Goel V. Sketches of thought. Cambridge, Mass.: MIT Press; 1995.

[35] Davies S.P. Characterizing the program design activity: Neither strictly top-down nor globally opportunistic. Behaviour and Information Technology 1991; 10(3): 173-90

[36] Guindon R. Designing the design process: Exploiting opportunistic thoughts. $\mathrm{Hu}-$ man-Computer Interaction 1990; 5(2): 305-44. 
[37] Darke J. The primary generator and the design process. Design Studies 1979; 1(1): 36-44.

[38] Kelley T., Littman J. The art of innovation: Lessons in creativity from IDEO, america's leading design firm. London: Profile Books; 2004.

[39] Tuulenmäki A. Concepts in uncertain business environments. In: Keinonen T, Takala R. (eds.) Product concept design: A review of the conceptual design of products in industry. New York, NY: Springer; 2006. p157-75.

[40] Pahl G., Beitz W., Feldhusen J., Grote K.-H. Engineering design: A systematic approach. 3rd English ed. New York: Springer; 2007.

[41] Ulrich K.T., Eppinger S.D. Product design and development. 4th ed. Boston: McGraw-Hill/Irwin; 2008.

[42] Restrepo J., Christiaans H. Problem structuring and information access in design. Journal of Design Research 2004; 4(2): DOI: 10.1504/JDR.2004.009842

[43] Yen C.C., Jiang H. Design thinking in different disciplines. In: "The Future is" 2012 Eastman/IDSA Education Symposium, IDSA 2012 international conference; Aug 15-18; Boston 2012.

[44] Dorst K., Dijkhuis J. Comparing paradigms for describing design activity. Design Studies 1995; 16(2): 261-74.

[45] Prince M.J., Felder R.M. The many faces of inductive teaching and learning. Journal of College Science Teaching 2007; 36(5): 14-20.

[46] Prince M.J., Felder R.M. Inductive teaching and learning methods: Definitions, comparisons, and research bases. Journal of Engineering Education 2006; 95(2): 123-38.

[47] Jonassen D.H., Hung W. All problems are not equal: Implications for problem-based learning. Interdisciplinary Journal of Problem-Based Learning 2008; 2(2): 4.

[48] Kolmos A., Kuru S., Hansen H., Eskil T., Podesta L., Fink F., et al. Special interest group B5 "problem based and project oriented learning". Erasmus Thematic Network Project: TREE-(Teaching and Researc in Engineering Education) in Europe, 2007.

[49] Graaff E.d., Kolmos A. Characteristics of problem-based learning. International Journal of Engineering Education 2003; 19(5) 657-62.

[50] Lee N. Project methods as the vehicle for learning in undergraduate design education: A typology. Design Studies 2009; 30(5): 541-60.

[51] Jonassen D.H., Strobel J., Lee C.B. Everyday problem solving in engineering: Lessons for engineering educators. Journal of Engineering Education 2006; 95(2): 139-51.

[52] Dochy F., Segersb M., Bosscheb P.V.d., Gijbelsb D. Effects of problem-based learning: A meta-analysis. Learning and instruction 2003; 13(5): 533-68. 
[53] Kan J.W.T., Gero J.S. Using the FBS ontology to capture semantic design information in design protocol studies. In: McDonnell J, Lloyd P. (eds.) About: Designing: Analysing design meetings: CRC Press; 2009. p213-29.

[54] Lloyd P., Scott P. Discovering the design problem. Design Studies 1994; 15(2): 125-40.

[55] NUS DCC. The design-centric engineering curriculum (DCC). http:// www.eng.nus.edu.sg/ugrad/ dcc/index.html/ (accessed in 23 Sep 2011). 